\title{
Bladder Anastomotic Leak, CTCAE
}

National Cancer Institute

\section{Source}

National Cancer Institute. Bladder Anastomotic Leak, CT CAE. NCI Thesaurus. Code C143318.

A finding of leakage of urine due to breakdown of a bladder anastomosis (surgical connection of two separate anatomic structures). 